\title{
SUSTAINABILITY TRENDS IN THE POSTAL SYSTEMS OF LAST-MILE DELIVERY
}

\author{
Dragan Lazarević1 ${ }^{1}$ Momčilo Dobrodolac ${ }^{1 *}$
}

\begin{abstract}
Postal systems are characterized by strong infrastructure and appropriate human, technical, and technological resources. The activities of these systems are economically demanding and impact the environment, which represents some of the most delicate problems of sustainable development. This paper presents the basic principles and proposals for the improvement of sustainable development capabilities in the postal systems. A review of modern means of transport is offered. Some of these means are still in the trial phase; however, their implementation is expected in the near future based on both, economic and environmental reasons.
\end{abstract}

Keywords postal system, transport, last-mile delivery, sustainable development

\section{INTRODUCTION}

The postal system at the global level includes individual systems, composed of a large number of postal companies. Every postal company, whether it is a private or public postal operator (PPO), is based on a branched network throughout the territory where it provides services. This territory may include a part of a district or a specific city, the whole territory of a city, a state, or a region. However, if we consider the postal system as unique or global, we can conclude that almost every inhabited territory on the planet is covered by the services of at least one operator. Accordingly, it can be concluded that the global postal system is dimensionally one of the largest business systems that exist (Dobrodolac et al., 2018). The postal system includes a highly developed distributive network, whose basic characteristics are the great number of postal items, plenty of business and customers' subjects and developed infrastructure. The functioning of such a system has an important effect on the environment (Lazarević et al., 2015).

Universal Postal Union (UPU), which enacts some regulations, decisions, and strategies in the functioning of postal activity, has a key role in the business of postal companies at a global level. UPU initiated the Program of environmental protection in 1994, founding the Working group for environmental issues. At the same time, the Project group for sustainable development was founded (the Sustainable Development Project Group) to enable support to the operators in their efforts to integrate sustainable development into their business (Pejčić Tarle et al., 2012). Three main dimensions of sustainable development are the following: Economic, Environmental, and Social. To achieve the goal of sustainability, it is necessary to act through all of these three dimensions. Postal operators should satisfy the needs of the population, their needs through the economic profit, but also to accomplish the principles of environmental protection. In October 2012, on the 25th UPU Congress in Doha, Postal Strategy was adopted for the period 2013- 2016, which defines as one of the four aims the promotion of sustainable development of the postal sector

\footnotetext{
${ }^{1}$ University of Belgrade, Faculty of Transport and Traffic Engineering, Department of Postal Services and Networks, Vojvode Stepe 305, 11000 Belgrade, Serbia

*corresponding author, phone: +381 113091 213, e-mail: m.dobrodolac@sf.bg.ac.rs
} 
(Universal Postal Union, 2012). Based on this strategy and the earlier efforts, many postal operators started to apply the global mission of sustainable development through various tendencies and sustainability policies. At the $26^{\text {th }}$ UPU Congress in Istanbul (2016), there was also a discussion about sustainable development. It is said that the member countries and/or their designated operators shall adopt and implement a proactive sustainable development strategy focusing on environmental, social, and economic activity at all levels of postal operations and promote sustainable development awareness. The following aspects of environmental protection are listed (Universal Postal Union, 2018): Designated operators should make their products and services as environmentally friendly as possible within the limits imposed by technologies and resources; The consumption of materials and energy should be optimized and be the minimum consistent with the efficient conduct of operations; Materials used should comply with non-pollution or non-toxic standards established by the relevant national and international agencies; Designated operators should promote the recycling of paper and other materials. They should also promote the use of recycled materials.

One of the most sensitive phases to organize in the postal process is last-mile delivery. The traditional approach at this stage involves the use of road transport, which has a significant impact on the sustainability of the system, both financially and environmentally. Namely, it is necessary for the vehicle fleet of postal companies to be extensive, which implies the existence of a large number of different means of transport. As a result, investment and maintenance costs increase. Besides, road transport, through emissions, has a significant negative impact on the environment (Lazarević et al., 2020). It is not uncommon for the fleets of postal companies to be worn out, which makes the previously mentioned problems even more significant. One of the ways to improve this segment is the analysis and implementation of modern, sustainable delivery systems that rely on the use of unmanned aircraft - drones and autonomous vehicles, tube transport, and e-bike.

It is clear that in order to achieve the sustainability of the global postal system and profit efficiency (Ralević et al., 2015), it is necessary to implement appropriate activities within individual postal systems. The subject of the paper is to examine the basic indicators of sustainable development in the postal system. The goal of the paper is to define activities and solutions that should contribute to the improvement of the postal system in the field of sustainability and efficiency.

\section{MATERIALS AND METHODS}

The methodology which is applied, primarily related to the analysis of trends in the field of sustainability of postal companies, can be presented in three steps:

- $1^{\text {st }}$ step: Analysis of available literature related to the sustainable concept in postal companies;

- $2^{\text {nd }}$ step: Analysis of the business process of postal companies and all phases in the transfer of postal items.

- $3^{\text {rd }}$ step: Isolation of indicators and influencing factors on the sustainability of postal companies, as well as activities and ways that can contribute to its improvement.

The proposed methodology aims to single out the appropriate activities and their analysis in terms of the impact on the sustainability of the operations of postal companies with an emphasis on the last-mile delivery phase. By applying the methodology, the possibilities of modern delivery systems were pointed out. Also, the phases of receiving, sorting, and transporting shipments were analyzed.

\section{THEORETICAL BACKGROUND OF THE SUSTAINABLE DEVELOPMENT TRENDS IN THE POSTAL SYSTEM}

Despite different development of some postal operators and systems, a trend valid for all refers to the approach to the concept of sustainable development. Under the authority of Universal Postal Union and 
according to the strategy from Doha, that has been adopted, postal operators are concentrated on this concept step by step. The economic dimension of sustainable development has been distinguished as an alarming dimension. More than 600000 posts in the world form a postal system, which becomes the largest global and distributive network on the planet. More than 1500000 vehicles, a large number of motorcycles and airplanes are being used daily to accomplish postal service. Production, technical and technological systems, and employees require energy consumption and another kind of energy every day such as water, paper, etc., which have a negative impact on environmental issues. To reduce this negative impact, all stakeholders must take part in it. Also, it is essential that all companies and organizations accomplish their aims and business policy according to the environmental protection and negative emissions reduction (Universal Postal Union, 2011; Lazarević et al., 2015). In 2008, the postal operators received the first questionnaire from Universal Postal Union for greenhouse gas emissions. The goal of this questionnaire, which consists of three parts is to determine the fuel consumption on an annual basis, as well as the number of passed kilometers for each vehicle and the amount of fuel and electric energy for lighting, heating, microclimate maintenance, and other daily consumption. Considering the low level of replies in the first year (mainly because it is not possible to easily gather the data), the questionnaire was carried out again in 2009. The standard protocol, that refers to the emissions reduction and environmental protection, is based on the internationally accepted resources in this field, such as GHG (Greenhouse Gas) protocol WRI/WBCSD (World Resources Institute and World Business Council for Sustainable Development), International Energy Agency, Global Reporting Initiative (GRI) and ISO 14000 standard. The purpose of that document is to identify all emissions resources that come from the postal activities (Universal Postal Union, 2009; Lazarević et al., 2015; Lazarević et al., 2020). Although the problem of the sustainability of the postal system was mentioned in the years preceding the 25th UPU Congress in Doha, the guidelines adopted at this Congress are the main trigger for the implementation of sustainable development activities in the postal system. Four programs are defined (Universal Postal Union, 2012):

- Improve remuneration systems between designated postal operators - Fair and appropriate remuneration systems among designated operators, in line with market needs and conditions, form the basis of a well-functioning and sustainable international postal network. Remuneration systems that benefit some designated operators but penalize others are not sustainable in the long term. If left unchecked, they jeopardize the sustainability of a universal network. Action is required to harmonize and improve the different remuneration systems for the various postal products (e.g. letters, packets, parcels, EMS).

- Strengthen the UPU's capacity to respond appropriately to changing needs in the market - Adapt UPU structures, as well as national regulatory frameworks, to the changing needs of the markets. There are two aspects to the objective: first, to make sure that the UPU and its structure remain relevant for its member countries at a time when governments tend to consider postal services no more important than any other commercial activity; and second, to facilitate the broad exchange of views and best practices with respect to postal market developments.

- Stimulate the inclusion of all segments of the population through greater and/or targeted access to postal services - The postal network is an asset that can be leveraged to increase financial and social inclusion. This program seeks to use the postal network to advocate and foster financial inclusion, as well as the provision of basic government and communications services to people in remote areas.

- Promote environmental awareness and social responsibility - Put a framework in place to allow the postal sector to develop in a sustainable way. The UPU has expanded its environmental activities by promoting best practices and measuring the impact of the postal sector on the environment. In this area, synergies with other organizations should be encouraged. At the same time, in cooperation with other United Nations organizations and within the framework of the UN Millennium Development Goals, the UPU has used the postal network to help raise awareness of key social issues, such as the fight against HIV/AIDS. These kinds of activities should feature 
prominently on the UPU's sustainable development agenda. Finally, the UPU should continue to promote social dialogue and decent working conditions within the postal sector.

Defined programs and adopted guidelines are still the mechanisms and tendencies that postal operators are striving for. 26th UPU Congress in Istanbul (2016), there was also a discussion about sustainable development. One of the three main goals of the adopted strategy is - Ensure sustainable and modern products. One of the curiosities was that it is the 26th Universal Postal Congress made strides in sustainability as the first "paper smart Congress", meaning the majority of documents have been presented to delegates in electronic format.

\subsection{Sustainable development in the process of postal services providing}

Providing postal service implies the reception of items and their sorting, transport, and delivery to the recipient. These are basic parts of sub-systems in the providing of postal service. In the complex process of distribution where a customer is the main actor, from reception to the delivery, it is necessary to manage the items, information, and people's flow at the same time, requiring on this way that operator possess the new equipment and organization (Bojković et al., 1999).

\subsubsection{Reception of postal items and sustainable development}

The reception of postal items is performed in the units of the postal network via postal clerks and on the terrain via couriers or postal mailboxes. The units of the postal network enable the possibility of postal items reception on their post office counters. The reception is carried out by a postal clerk, using the necessary equipment. The reception of items via couriers refers mainly to the express services.

Tab. 1 Sustainable development on the reception of postal items; source: authors

\begin{tabular}{ccc}
\hline $\begin{array}{c}\text { Impacts } \\
\text { pnused } \\
\text { outdated and } \\
\text { energy } \\
\text { ineffective } \\
\text { computer } \\
\text { configuration }\end{array}$ & $\begin{array}{c}\text { The way of acting } \\
\text { Introduction of new } \\
\text { technologies, e.g. } \\
\text { hardware and } \\
\text { software } \\
\text { virtualization }\end{array}$ & $\begin{array}{c}\text { Increase of system's use, reduction of required resources } \\
\text { and systems for their feed, development of green IT }\end{array}$ \\
$\begin{array}{c}\text { Outdated } \\
\text { systems for } \\
\text { franking and } \\
\text { unreliable } \\
\text { scales }\end{array}$ & $\begin{array}{c}\text { Purchase of new } \\
\text { efficient franking } \\
\text { machines and } \\
\text { introduction of new } \\
\text { more qualified } \\
\text { electronic scales }\end{array}$ & $\begin{array}{c}\text { Increase of energy efficiency, noise reduction, increase of } \\
\text { efficiency of counter's place }\end{array}$ \\
\hline $\begin{array}{c}\text { Inappropriate } \\
\text { territorial } \\
\text { organization } \\
\text { and schedule of } \\
\text { couriers }\end{array}$ & $\begin{array}{c}\text { Constant tracking } \\
\text { and analysis of } \\
\text { customers' } \\
\text { requirements }\end{array}$ & $\begin{array}{c}\text { Establishment of the appropriate territorial organization } \\
\text { and schedule of couriers, which should prevent }\end{array}$ \\
\hline $\begin{array}{c}\text { Inefficient } \\
\text { preventive delays in receiving items, but also to efficiently } \\
\text { perform the service with certain savings. }\end{array}$ \\
$\begin{array}{c}\text { Application of } \\
\text { couriers } \\
\text { transport items }\end{array}$ & $\begin{array}{c}\text { appropriate tools and } \\
\text { algorithms for } \\
\text { finding the best route }\end{array}$ & $\begin{array}{c}\text { Defining the best (the most efficient, the cheapest ...) } \\
\text { route, which will be the most environmentally and cost- } \\
\text { effective }\end{array}$ \\
\hline
\end{tabular}

Post office counters in the units of the postal network are workplaces, which contain certain equipment, necessary for the clerk's work. Equipment means computer terminal, precise electronic scales, franking machines, and the other extra equipment. Reception of items via courier implies that a sender will contact the call center, then this application will be forwarded to the courier, that goes to the address and accomplishes the reception of postal items. It is essential to pay attention to the processes, which are on 
the border with economic profitability and affect the environment. Driving to the address of the reception and later transport of postal items are basic influential factors. Postal mailboxes are set on certain locations in certain areas, manly of narrow city districts. The organization of visiting these locations and collection of items by a postal employee is not enough developed, i.e. the emptying of mailboxes is not often. This kind of reception of postal items is not enough developed in the real system. In an ideal case, the presence of a mailbox increases significantly availability to the postal system. There's no need for clients to use transport means to the mailbox because the locations are various. Therefore it contributes notably to the cost reduction and environmental protection (Lazarević et al., 2015). Table 1 shows the appropriate impacts (indicators) on sustainable development in the reception segment as well as the proposed activities (solutions) and the aim of their realization.

\subsubsection{Sorting of postal items and sustainable development}

Sorting of postal items represents the process of items classification based on the addresses, by destination. The classification is the complex logistic process that generates maintenance costs, electricity consumption, etc. Overload mechanization and systems for items classification have the biggest potential for improvement according to the sustainable development in this part of postal service providing. Table 2 shows the appropriate impacts (indicators) on sustainable development in the sorting segment as well as the proposed activities (solutions) and the aim of their realization (Lazarević et al., 2015).

Tab. 2 Sustainable development on the sorting of postal items; source: authors

\begin{tabular}{ccc}
\hline Impacts & The way of acting & Aim \\
\hline $\begin{array}{c}\text { System of main } \\
\text { transport flow }\end{array}$ & $\begin{array}{c}\text { Use of the most modern means, } \\
\text { low energy consumers, tracking } \\
\text { the flow of items and its } \\
\text { analysis }\end{array}$ & $\begin{array}{c}\text { Use of energy-efficient and economically } \\
\text { profitable systems and system of increased } \\
\text { productivity according to the right } \\
\text { dimensioning }\end{array}$ \\
\hline $\begin{array}{c}\text { Tracking and efficiency analysis } \\
\text { of outdated systems, delay in } \\
\text { the use of self-sustaining } \\
\text { systems }\end{array}$ & $\begin{array}{c}\text { systems, such as gravity means } \\
\text { and ejection from the use of } \\
\text { ineffective }\end{array}$ & $\begin{array}{c}\text { Reduction of energy consumption and } \\
\text { negative impact on the environment with the } \\
\text { delay level of system efficiency }\end{array}$ \\
\hline $\begin{array}{c}\text { Capacity } \\
\text { dimensioning }\end{array}$ & $\begin{array}{c}\text { Tracking of the items transfer } \\
\text { and analysis of their flow }\end{array}$ & $\begin{array}{c}\text { Right dimensioning of a system for } \\
\text { classification }\end{array}$ \\
\hline
\end{tabular}

\subsubsection{Transport of postal items and sustainable development}

For purposes of postal items transport, the means of road traffic, air traffic, and ship transport are being used. Various factors have an impact on sustainable development of this sector: different characteristics of transportation mode, regulatory and legislative bodies, providers of services, financial systems, technologies of land use, and behavior of people, which take part on all levels and all segments of the system. Transport is in rapid growth, and accordingly, it represents the sector with the fastest growth of environmental pollution (Bojković and Pejčić Tarle et al., 1999). Road transport is one of the greatest pollutants of air, water and ground, noisy, etc. (Lazarević et al., 2015). The satisfaction of sustainable development in road traffic can be achieved in many ways (Pejčić Tarle et al., 2009). Two ways that are often applied are the following: combined ground transportation and the use of alternative fuels in road traffic. Combined ground transportation is being used in postal traffic, which includes road and railway traffic. Combined transport is the solution that has all advantages of transport modes, which take part in it. On the other hand, there is a need that all deficiencies should be minimized. Also, sometimes, because of the geographical limits, it is not possible to accomplish direct transport, but the combined transport is being used. The sector of road traffic cannot be replaced, but its economic and ecological impact is not on a good level. The basic cause, for mentioned bad impacts, is the fact that it is expensive and "dirty" fuel that is used. In the road transport of postal items, diesel and petrol are mostly being used as fuel. The use of alternative fuels is necessary and it reduces the negative impact on the environment. Table 3 shows the 
appropriate impacts (indicators) on sustainable development in the transport segment as well as the proposed activities (solutions) and the aim of their realization (Lazarević et al., 2015).

Tab. 3 Sustainable development on the transport of postal items; source: authors

\begin{tabular}{|c|c|c|}
\hline Impacts & The way of acting & Aim \\
\hline $\begin{array}{l}\text { Energy } \\
\text { efficiency }\end{array}$ & $\begin{array}{l}\text { Combination of road and railway } \\
\text { traffic, wherever it is possible } \\
\text { and deadlines permits }\end{array}$ & $\begin{array}{c}\text { Railway traffic is more energetically more efficient, } \\
\text { with its role it increases the total energy efficiency } \\
\text { of the system. }\end{array}$ \\
\hline Mobility & \multirow{2}{*}{$\begin{array}{l}\text { Combination of road and railway } \\
\text { traffic, wherever it is possible } \\
\text { and deadlines permits }\end{array}$} & $\begin{array}{l}\text { Road traffic has notably better mobility, with its } \\
\text { role, it increases the total system mobility }\end{array}$ \\
\hline Costs & & $\begin{array}{l}\text { Including the savings of both systems, total costs } \\
\text { are being reduced }\end{array}$ \\
\hline $\begin{array}{l}\text { Negative } \\
\text { impact on } \\
\text { the } \\
\text { environment }\end{array}$ & $\begin{array}{l}\text { The use of renewable resources } \\
\text { to the level of their regeneration } \\
\text { and use of non-renewable } \\
\text { resources to the level of } \\
\text { possibility of renewable } \\
\text { substitute development }\end{array}$ & Reduction of negative impact on the environment \\
\hline
\end{tabular}

The basic principles of sustainable development in part of postal items delivery, we can consolidate through the perception of sustainable development parameters of some activities in the segment of items reception and transport. New trends in the last-mile delivery of the postal item, which will be discussed below, can contribute to sustainable development in this segment, but also at the level of the entire postal system.

\section{NEW TRENDS IN THE POSTAL ITEMS DELIVERY AND SUSTAINABLE DEVELOPMENT}

Delivery of the postal items represents the last and one of the most important activities in the process of their distribution to the users. Modernizing the delivery system is an essential step to effectively respond to user requests and possible unforeseen situations, which can be a disruptive factor. Due to the numerous possibilities it offers, the application of new technologies for this purpose is a convenient solution. In the field of organization and technological development of items and packages, the most up-to-date tendencies relate to the development of last-mile delivery systems for the use of unmanned aircraft - drones and autonomous vehicles, tube transport, and e-bike. The application of these systems should have a positive impact on sustainable development.

\subsection{Delivery by drone}

The drone is a type of unmanned aircraft. The most common and traditional use of drones is for military purposes, but more and more are being tested for their use in various special services (police, fire-fighters, health care ...) and civil sectors (various forms of delivery, agriculture ...). Drones consist of a large number of technologically advanced components, which enable them to operate efficiently and reliably. In addition to physical parts, software support, which is a connection between the parts, the drone, and the control center, is also very important, and together with the sensors and between the drones and the environment (Kharchenko \& Prusov, 2012).

Based on the technology they use in flying, the drones are divided into two basic types:

- Independent aircraft - a drone flying autonomously according to pre-defined and stored data;

- Remote control drone - The flight is controlled via remote control, operated by a pilot (operator, navigator ...). 
The basic advantages of drones in the field of delivery of packages relate to their speed, the ability to access difficult terrain and remote locations, overcoming obstacles and potential traffic congestion, positive environmental impacts, etc. In addition to numerous advantages, there are numerous limitations. First of all, the underdeveloped and defined legislation, low transport capacity, the possibility of errors due to incorrect GPS data (Aurambout, 2019; Chen et al., 2019).

Amazon and DHL are companies that are among the first to test the delivery by drone and work on their development. One very positive argument to consider is that drones can increase the delivery time available. Based on the tests carried out, by Amazon (the territory of Chattanooga, Tennessee), there have been some indications of the functioning of the drones in the delivery system. First of all, the cost of the package delivered to the drone, depending on certain details, is about $\$ 0.07$, while the cost of the courier per package is about $\$ 1.2$. Significantly lower costs of delivering packages compared to the traditional way are noticeable. As the market and the use of truncheons expand in the future, this cost will be further reduced. On the other hand, there are additional costs that are not introduced into the analysis, and they relate to investments in the drone stations (Welch, 2015). Legislation and permits in this area are not regulated in many countries. Figure 1 shows Amazon's general drone delivery concept.

The drive that the drones use is based on an electric battery. For this reason, their positive impact on the preservation of the environment is extremely important. Positive economic performance, as well as ecological characteristics, represents the basic potential of drones to contribute to the sustainable development of the postal system through the delivery system of items. The positive impact on the sustainable development of the postal system is reflected in the following:

- Lower costs - better economic performance;

- The use of environmentally cleaner drives - minimum emissions of harmful gases;

- Indirect reduction of harmful emissions due to reduction of the number of delivery vehicles;

- It indirectly affects the reduction of congestion in traffic;

- The ability to access difficult terrain and remote locations;

- Expanding territorial accessibility which is of great importance for users.

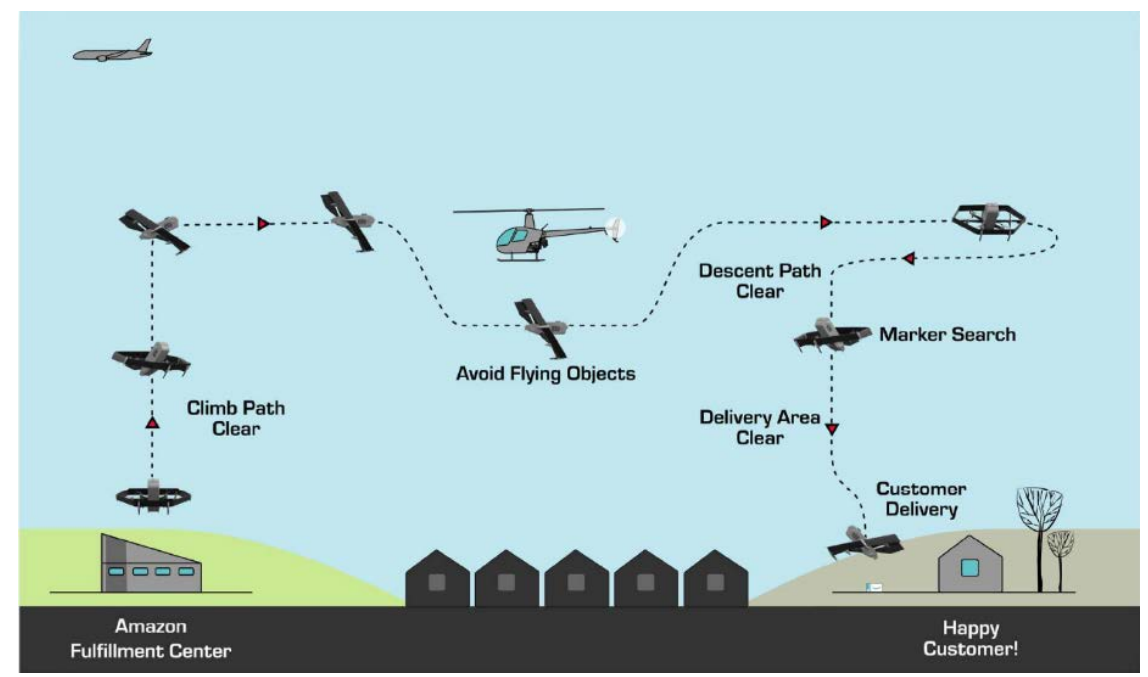

Fig. 1 Amazon Prime Air's general concept of operations; source: (Garrett-Glaser, 2019) https://www.aviationtoday.com

\subsection{Delivery by autonomous vehicles}

After the introduction of automatic dispatch processing machines, the automation of other parts of the chain of postal items was started. At this point, various pilot projects for the use of autonomous vehicles are being implemented worldwide as solutions for automated delivery or collection of shipments. The first 
delivery by autonomous truck took place on October 25, 2016, between Fort Collins and Colorado Springs (Čupić et al., 2017).

The potential application of autonomous vehicles in the postal sector is divided into two main categories: delivery to the end-user - last-mile delivery and line transport of items. Five suitable technologies are identified (United States Postal Service, 2017):

- An autonomous vehicle operated by a delivery agent - is a semi-autonomous vehicle in which the delivery agent is located, who can manage or perform the tasks of preparing or optimizing the delivery route while the vehicle carries a greater part of the responsibility for driving. Certainly, upon arrival at the desired address, the delivery agent realizes the delivery;

- An autonomous vehicle parked independently - the activity of finding parking spaces by the delivery agent can negatively affect the efficiency of the delivery process. A vehicle that only locates parking eliminates this problem. After the delivery agent turns on the parking assistant and leaves the vehicle, the vehicle only finds the closest available parking space. After the delivery has been completed, the delivery agent finds the location where the vehicle is located via GPS coordinates.

- An autonomous vehicle tracking delivery agent - This approach is based on the concept that the vehicle is accompanied by a delivery agent who moves on foot so that the items are always nearby (no loss of time to go to the parked vehicle). This reduces the fatigue of the delivery agent and diminishes the possibility of his injury.

- An autonomous vehicle that complements the number of items on delivery - it implies that at some point in the delivery process the vehicle goes only to the postal network unit on the supplement of the items, and then returns on the route to the delivery point.

- Mobile packing box - the vehicle contains partitions that act as mailboxes for themselves. Charged with items, the vehicle would go on delivery, and users could access through the code or bar code to the appropriate partition and take over the items.

Due to the electric drive of the vehicle, their positive impact on the environment is remarkable. It would also indirectly affect the reduction of the number of vehicles that are significant polluters of the environment. Economic indicators are not very accurate, but the fact that further development of technology will influence the increase in the economic availability of these systems (James, 2018).

Depending on which concept is being applied, the positive impact on the sustainable development of the postal system is reflected in the following:

- The use of environmentally cleaner drives - minimum emissions of harmful gases;

- Indirect reduction of harmful emissions due to reduction of the number of delivery vehicles;

- It indirectly affects the reduction of congestion in traffic;

- Reducing the possibility of injury of the delivery agent;

- More efficient use of the cargo space-saving time, reducing the number of departures on delivery...

Based on the above-mentioned characteristics and possible impacts, it is concluded that the implementation of these innovative systems can lead to the improvement of the sustainable development of the postal service. Also, attention should be paid to different variants of combined delivery.

One of the biggest technical challenges in the development of autonomous delivery systems is the development of the system of movement and perception of obstacles by vehicles. Figure 2 shows an example where an autonomous vehicle moves on the sidewalk, where in addition to people, other obstacles can appear, such as animals, objects, as well as other autonomous vehicles. Besides, stable communication of the vehicle with the headquarters, but also with other vehicles in the vicinity, is important for the organization of delivery operations. 


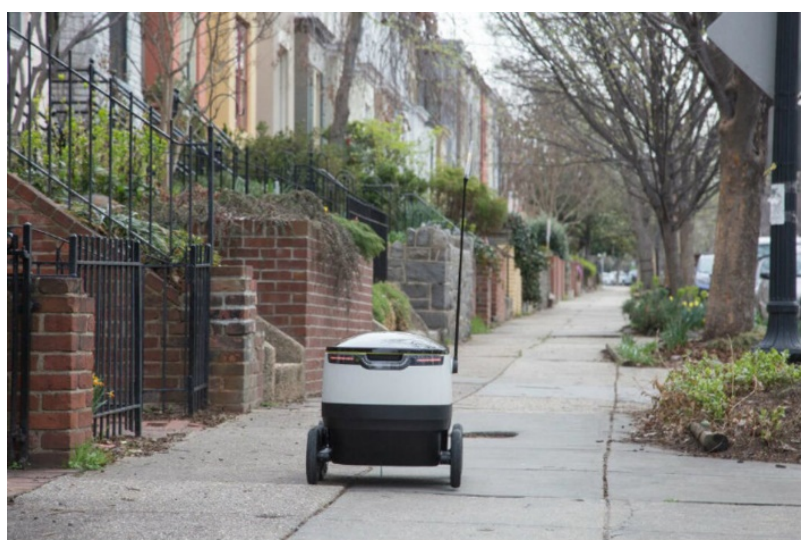

Fig. 2 Delivery by autonomous vehicle - driving on the sidewalk; source: (Ackerman, 2015) https://spectrum.ieee.org

\subsection{Delivery by e-bike}

The last-mile delivery concept, based on the use of e-bikes, is one of the suitable ways for rural, and especially for urban areas. One of the main reasons is requiring a minor public space, both during transport and parking. Besides, the positive environmental impact is very pronounced due to the mode of operation, which does not involve the direct combustion of fuels and emissions. In accordance with the above, it can be concluded that e-bike application in the system of delivery has a positive impact on public life, as well as on occupational health.

One of the disadvantages in the application of e-bikes in the last-mile delivery phase is the low load capacity and cargo space, which some companies have tried to mitigate by using specialized cargo bikes (Figure 3) (Choubassi et al., 2016; Rajesh \& Rajan, 2020). Also, the terrain configuration can be a limiting factor for their use, which the e-drive has alleviated compared to ordinary bicycles. The network of bicycle lanes is an important precondition for the application of this concept, which can be a significant limitation for its implementation.

Despite the mentioned limitations, the application of e-bike is a suitable concept for last-mile delivery, primarily due to the positive effect on the environment and the need for less financial investment, which can be useful primarily for smaller companies.

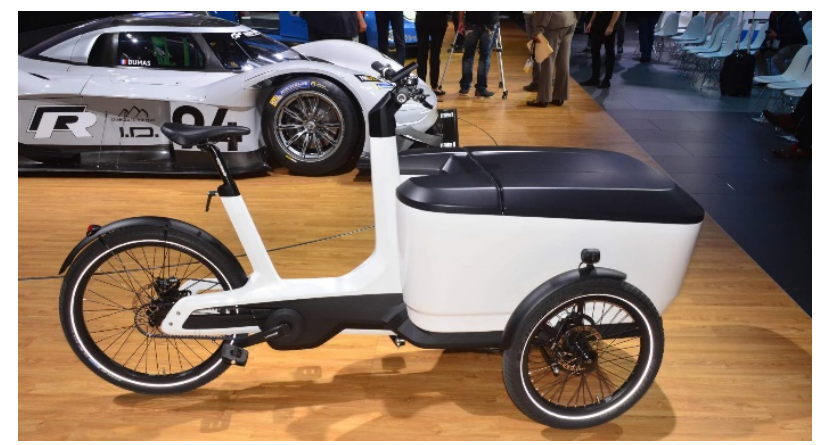

Fig. 3 VW cargo e-bike; source: (Mihalascu, 2018) https://www.carscoops.com

\subsection{Tube transport for last-mile delivery}

Tube transportation is a well-known concept in postal traffic. Pneumatic tube transport was used in the company's internal systems. However, modern sustainability trends, such as environmental impact and reduced use of public space, lead to this concept being applicable within the delivery phase. The basic principle involves the transfer of shipments in appropriate capsules through tubes (Figure 4). 
Depending on the project, the infrastructure of these systems can be above ground, underground, or combined, so the occupation of public areas can be minimal. Emissions are significantly lower compared to the traditional method of delivery, as well as the level of noise produced.

One of the main limitations is the low level of flexibility of the concept in terms of access points by users. However, it may be suitable for connecting internal points in systems of some other type of delivery, such as postomates, drone stations, autonomous vehicles, postal network units, etc.

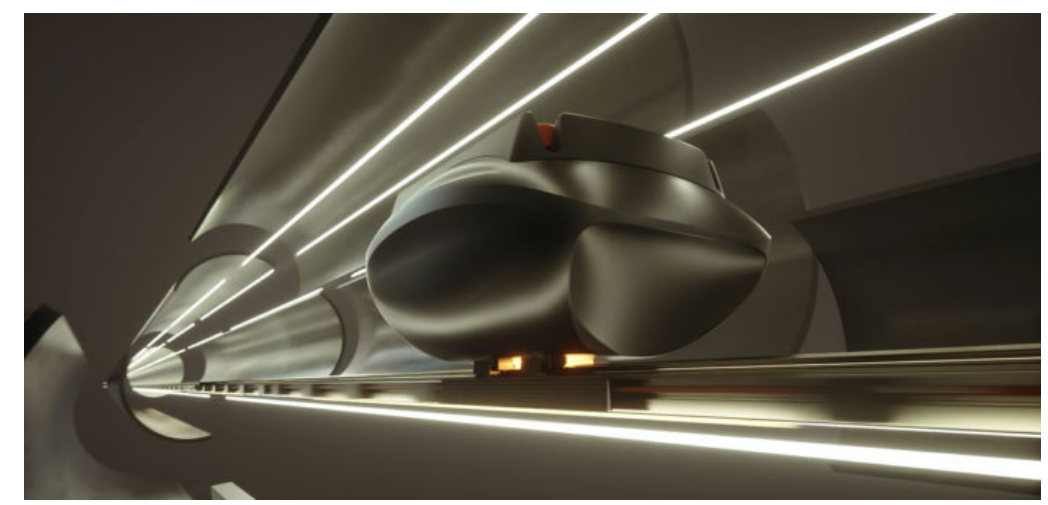

Fig. 4 Underground delivery network; source: (Norman, 2020) https://www.parcelandpostaltechnologyinternational.com

\section{DISCUSSION}

Last-mile delivery, as already mentioned, is a very sensitive phase in terms of sustainability, in the transfer of shipments and other types of goods. The results of the applied methodology determined the indicators and activities that can be implemented to improve the sustainability of the system. Different phases in the business process, such as a receipt, sorting, and delivery of shipments, are analyzed. Within the phase of receiving shipments, it is necessary to implement modern technological solutions, such as the introduction of virtualization technology, new devices with high energy efficiency and low noise in exploitation, necessary for reception activities. Besides, it is important to monitor the requirements and habits of users to better organize the service, primarily in terms of engaging different resources (analysis of the territorial organization, routes ...). During the sorting of shipments, a large number of different resources, human and machine, were engaged. Due to a large number of shipments in the system, their monitoring and analysis are of great importance, and above all because of the sizing of the required resources for their processing. The use of high-class shipment processing plants represents a significant chance to improve the sustainability of the system.

Transport is a phase that can be found within other phases, as a separate business process. The traditional approach implies dependence on road transport. For this reason, the economic and environmental dimensions of sustainability are significantly compromised. To improve them, it is necessary to implement a vehicle fleet that is based on the use of alternative fuels and new technologies (e-cars, e-bikes, drones, autonomous vehicles). Road transport is emerging and has a prominent impact on sustainability in the last-mile delivery phase. The analysis showed that the application of modern technological solutions at this stage can have a very significant impact on improving sustainability within each of the three dimensions. Last-mile delivery is not just a phase in the transmission of postal items but is an integral part of any delivery system. For this reason, various studies related to different delivery systems can be found in the literature. They mainly refer to the analysis of energy consumption and emissions originating from this phase (Van Loon et al., 2015; Oliveira et al., 2017), in contrast to the analysis in this paper, which included several phases in the transmission process, thus selected indicators and activities for improving sustainability within each of them. 


\section{CONCLUSIONS}

The impact of postal operators on the parameters of sustainable development is reflected through all segments which are necessary for the functioning of the postal system. It is of global importance that postal companies take the initiative that leads to sustainable business as soon as possible. This requires raising awareness first of management, and then indirectly to all employees in the system. Aspirations and activities in the process of promoting sustainable development are part of the strategies adopted at the congresses of the World Postal Union. Some of the most important approaches are the application of different business concepts and solutions, such as combined transport, the use of alternative and renewable fuels, the improvement of economic accessibility, etc. New technologies and innovative systems for performing appropriate activities in the process of shipments of items, such as the use of drones and autonomous vehicles for delivery, show great potential for the improvement of sustainable development through all its dimensions. In the future, the issue of sustainability of business systems will be increasingly sensitive. Postal companies, which together constitute a logistic system of enormous proportions, have the responsibility to act in accordance with the adopted strategies. In this way, it will give a good example of a successful and responsible business for smaller business systems.

\section{References}

Ackerman, E. 2015. Startup Developing Autonomous Delivery Robots That Travel on Sidewalks. IEEE Spectrum, [Online]. Available at: https://spectrum.ieee.org [Accessed: 09.05.2020].

Aurambout, J.P., Gkoumas, K. and Ciuffo, B., 2019. Last mile delivery by drones: an estimation of viable market potential and access to citizens across European cities. European Transport Research Review, 11(1), p.30.

Bojković, Z. and Pejčić Tarle, S. 1999. A new approach to service quality in transportation. Tehnika, 4, pp. 295-302.

Chen, M.F., Liu, Y.Q., Song, Y. and Sun, Q., 2019. A Contract Coordination Model of Dual-Channel Delivery between UAVs and Couriers Considering the Uncertainty of Delivery for Last Mile. Discrete Dynamics in Nature and Society, 2019.

Choubassi, C., Seedah, D.P., Jiang, N. and Walton, C.M., 2016. Economic analysis of cargo cycles for urban mail delivery. Transportation Research Record, 2547(1), pp.102-110.

Čupić, A., Blagojević, M. and Stanivuković, B. 2017. Possibilities of application of autonomous vehicles in delivery of postal items. Proceedings of the 35th Symposium on novel technologies in postal and telecommunication traffic. Belgrade, Serbia, pp. 81-91.

Dobrodolac, M., Švadlenka, L. and Lazarević, D. 2018. Trends in sustainable development in the postal sector. Proceedings of the 7th International Scientific Conference of the Faculty of Transport Engineering. Pardubice, Czech Republic, pp. 78-86.

Garrett-Glaser, B. 2019. Amazon Seeks FAA Approval for Prime Air Drone Delivery. Avionica Magazine, [Online]. Available at: https://www.aviationtoday.com [Accessed: 09.05.2020].

James, J.Q., 2018. Two-stage request scheduling for autonomous vehicle logistic system. IEEE Transactions on Intelligent Transportation Systems, 20(5), pp.1917-1929.

Kharchenko, V. and Prusov, D. 2012. Analysis of Unmanned Aircraft Systems Application in the Civil Field. Transport, 27(3), pp. 335-343.

Lazarević, D., Dobrodolac, M. and Švadlenka, L. 2015. Basic Principles and Proposals for the Improvement of Sustainable Development Capabilities in the Postal Systems. Proceedings of the 6th International Scientific Conference. Pardubice, Czech Republic, pp. 263-283. 
Lazarević, D., Švadlenka, L., Radojičić, V. and Dobrodolac, M., 2020. New Express Delivery Service and Its Impact on CO2 Emissions. Sustainability, 12(2), p.456.

Mihalascu, D. 2018. VW Cargo e-Bike Punches Above Its Weight With 463-Pound Payload. [Online]. Available at: https://spectrum.ieee.org [Accessed: 09.05.2020].

Norman, E. 2020. Magway exceeds crowdfunding target for underground delivery network. Parcel and Postal Technology International, [Online]. Available at:

https://www.parcelandpostaltechnologyinternational.com [Accessed: 09.05.2020].

Oliveira, C.M.D., Albergaria De Mello Bandeira, R., Vasconcelos Goes, G., Schmitz Gonçalves, D.N. and D'Agosto, M.D.A., 2017. Sustainable vehicles-based alternatives in last mile distribution of urban freight transport: A systematic literature review. Sustainability, 9(8), p.1324.

Pejčić Tarle, S. and Bojković, N. 2012. The European policy of sustainable development of transport, In Serbian: Evropska politika održivog razvoja transporta. Beograd: Saobraćajni fakultet.

Pejčić Tarle, S., Bojković, N., and Petrović, M. 2009. Globalisation, European integration and operationalization of the concept of sustainable transport. Ecologica, 16, pp. 273-279.

Rajesh, B.P. and Rajan, J.A., 2020. Sustainable performance of cargo bikes to improve the delivery time using traffic simulation model. FME Transactions, 48(2), pp.411-418.

Ralević, P., Dobrodolac, M., Marković, D. and Mladenović, S. 2015. The Measurement of Public Postal Operators' Profit Efficiency by Using Data Envelopment Analysis (DEA): a Case Study of the European Union Member States and Serbia, Engineering Economics 26(2), pp. 159-168.

United States Postal Service. RARC Report RARC-WP-18-001, 2017, Washington.

Universal Postal Union. Annual Report, 2012, Doha.

Universal Postal Union. Best practices for a greener postal sector, 2011, Bern.

Universal Postal Union. Convention Manual, 2018, Bern.

Universal Postal Union. Greenhouse gas global overview and mitigation project, 2009, Bern.

Universal Postal Union. The global roadmap for postal services, 2012, Bern.

Van Loon, P., Deketele, L., Dewaele, J., McKinnon, A. and Rutherford, C., 2015. A comparative analysis of carbon emissions from online retailing of fast moving consumer goods. Journal of Cleaner Production, 106, pp.478-486.

Welch, A. 2015. A cost-benefit analysis of Amazon Prime Air. Honors Theses. 